\title{
STUDIES ON VIBRATION OF SOME RIB-STIFFENED CANTILEVER PLATES
}

\author{
M. N. Bapu Ra0, P. Guruswamy, M. Venkateshwara Ra0 AND S. PaVithran \\ Structural Sciences Division, NationalAeronauticalLaboratory, \\ Bangalore-560017, India
}

(Received 15 August 1977, and in revised form 29 November 1977)

\begin{abstract}
An experimental study was carried out to determine the resonant mode shapes and frequencies of some rib-stiffened skew cantilever plates by holographic interferometry. The influences of varying the sweep back angle, the rib stiffness and the aspect ratio, and the effect of varying the boundary conditions at the root chord, on the frequencies and mode shapes were also investigated. Results of the above investigation and also those of a comparative study with the finite element solution obtained for some of the cases studied are presented and discussed.
\end{abstract}

\section{INTRODUCTION}

Rib-stiffened skew plates are commonly employed in the structures of many aerospace vehicles such as missiles, rockets and aircraft. It is therefore necessary to determine the vibration characteristics of such structures for design purposes. While extensive investigations have been carried out in respect to unstiffened plates, similar studies regarding the stiffened plates appear to have been made on a relatively smaller scale. For brevity only a few of them will be mentioned here.

Lindberg and Olson [1] carried out response studies of a multi-bay panel system under random input, by using finite element methods. They also determined the vibration characteristics of an integrally stiffened panel subjected to a jet noise excitation [2]. Yurkovich et al. [3] carried out dynamic analysis of stiffened all round supported rectangular panel structures by both experimental and theoretical methods. Recently Durvasula [4] presented the results of his studies on the vibration problem of shaft-supported low aspect ratio wingtype structures. Various stiffened configurations were investigated by considering different combinations of the plate, the spar and the ribs. More recently Olson and Hazell [5] reported on the vibrational behaviour of stiffened square plates with all round fixed boundaries, as observed by holographic interferometric techniques. Very good experimental results in respect to mode shapes and frequencies, which were also in good agreement with those of theory, were obtained. But to the best knowledge of the present investigators, results of intensive studies on the vibrational characteristics of rib-stiffened cantilever skew plates have so far not been published.

In this paper, vibrational mode shapes and frequencies for some rib-stiffened skew cantilever plates, as determined by holographic interferometry, are presented. Effects of varying the sweepback angle, the rib stiffness and the aspect ratio, and also the effect of varying root-chord boundary conditions arising from the introduction of cuts at the root at different locations and of varying extents, on the vibrational behaviour of the plates have also been investigated. The purpose of this investigation was to carry out these parametric studies of stiffened plates in order to gain insight into their vibrational behaviour that is needed in the design of actual structures. In addition, it is appropriate to mention here that in the design of many guided rockets and missiles the edges are clamped over only a part of the root chord; or alternatively the root support may consist of a bending and shear-resisting 
hub at the mid-chord point and a shear-resisting pin at some other nnint away from the hub along root. For such situations the results of the present investigation on the effects of the cuts intheduced at the root chord can provide useful data for gaining better understanding

as to their vibrational behaviour.
Resonant frequencies were determined by the quadrature method in conjunction with a cathode ray oscilloscope. and the associated modes by the time-averaged holographic method. Real time holographic interferometry can provide extremely accurate values for resnanit which frequencies, and mode missing can seldom occur with this techniaue. This technique, was developed in the later stages of the present investigation, was employed for studying only a few of the cases considered for vibration testing. In addition, calculated results for some cases were cabtained by the finite element method. Results from the theoretical and experimental comparison study are presented for all cases studied and discussed.

\section{HOLOGRAPHIC INTLIRILEROMETRY}

Resonant mode shapes are determined by using timc-iveraged holographic interferometry, in which interference between images corresponding to two peak displacement positions of a vibrating object is obtained in a single exposure. In this method the exnosure time is much than the period of oscillation of the vibrating object. The holographic plate is exposed 18 nower scattered light from the vibrating object in cach position the obiect assumes during exposure. However the holugram formed will record most densely the reflected wave fronts corresponding to the peak displacement positions (ferto velucity positions) in which the object spends most of the exposure time interval. On reconstruction the hnloram displays the stationary nodal areas brightly as in the normal holugram, but the intinodes are seen contoured by fringes of equal displacement [o].

In the real time holographic technique a holopram of the object in its unloaded state is first recorded and processed in situ. The reconstructed wave front of the object is then allowed to interfere with the light siattered by the object suljocted to vibration; the resulting interference pattern represents the nodal and anti-nodal regions of the vibrating object.

2.1. IXCTTATION AND DITIRMINATION OI NATURAL FRIOUI:NC'LS

The natural frequencies were determined by conducting a resonance test, the excitation equipment consisting of an electronic oscillator, $60 \mathrm{~W}$ power amplifier and an acoustic exciter, in conjunction with a cathude-ray oscilloscope (C'RO).

The response was measured through the use of a magnetic pick-up which was moved around

to ensure that no mode was missed on account of the pickulp being close to or in

nodah areas frequencies were determined by using the principle of 1 issigous figures, in which a comparison is made of the philses of the exciting fince and response in the C'RO. When a

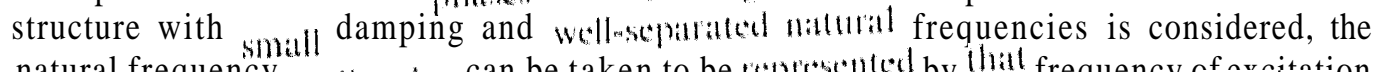
natural frequency ofvithation can be taken to be represenled by that freauency pavnitntion at which the phase diflerence between the force ami displatentent is t). This technique which
determining the resonant frequency was cmployed in association with the
holography which was used lor the determination of associated mode shanes.

The quadrature response method, as empliyed in the present study, hits been chosen in preference to the far more atcurate Kennedy Pinculechnique in view of the simplicity and rapidity with which the frequencies can be determined in the former case with reasonable

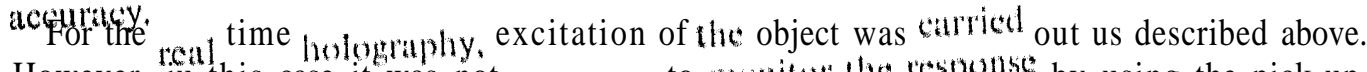

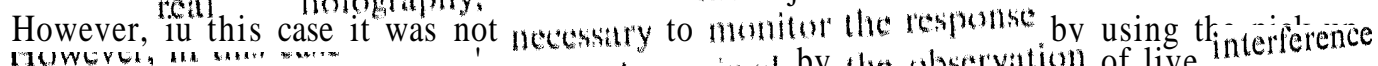
nowead the resonant frequencies were determined by the observation of live 


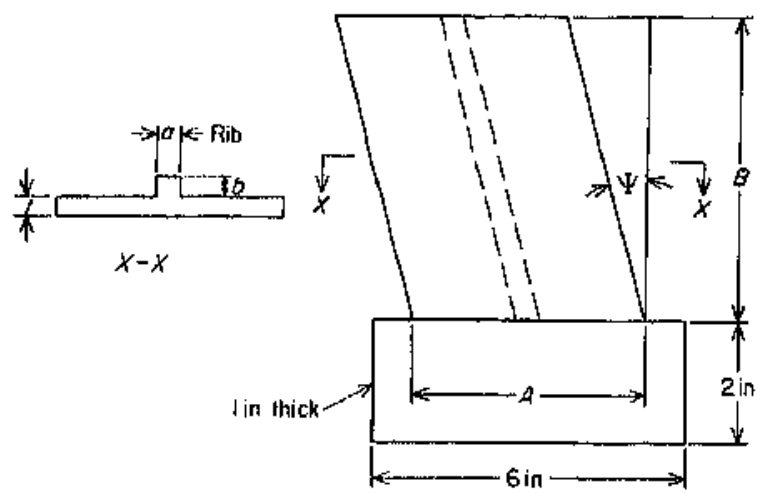

Figure 1. Structural details of the rib-stiffened plate model.

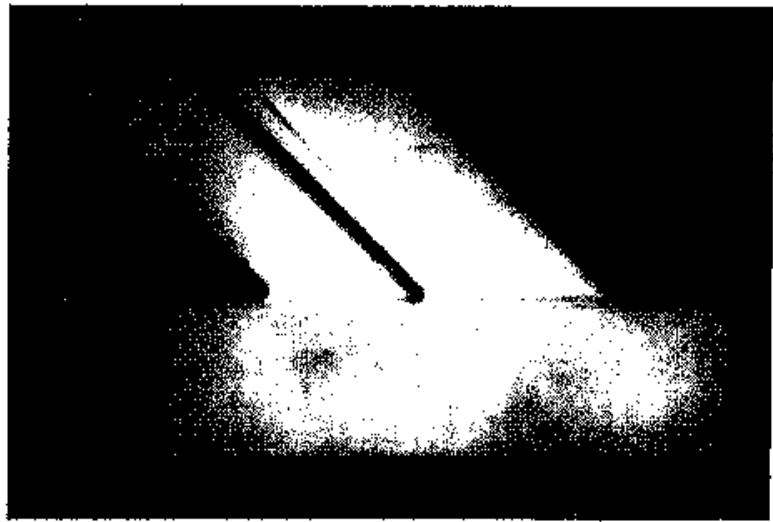

Figure 2. Integrally machined plate model with a rib.

fringes obtained by the vibration of the object, which become stationary and sharp whenever the oscillator is tuned to a resonant frequency. The amplitude of vibration can then be adjusted to the desired fringe distribution which represents the nodal and anti-nodal regions of the associated mode shapes. In this method all resonant frequencies can be scanned with just one hologram,

The resonant frequencies were recorded with the aid of a frequency counter.

In order to obtain realistic experimental conditions the rib-stiffened plate models as employed in the test were integrally machined from 1 inch thick mild steel plates, with the

TABU! 1

Structural and material properties of rib-stiffeneplates

\begin{tabular}{ccccc} 
Case & $\begin{array}{c}\text { Plate } \\
\text { dimension }\end{array} \quad \begin{array}{c}\text { Thickness } \\
\text { of the plate, } \\
t(\mathrm{~mm})\end{array}$ & $\begin{array}{c}\text { Rib } \\
\text { dimension } \\
(\mathrm{mm})\end{array}$ & $\begin{array}{c}\text { Sweep back } \\
\text { angle } \psi \\
(\text { degrees })\end{array}$ \\
1 & $114 \times 114$ & 2 & $6.35 \times 6.35$ & 0 \\
$2 \mathrm{a}$ & $114 \times 114$ & 2 & $6.35 \times 6.35$ & 30 \\
$2 \mathrm{~b}$ & $114 \times 114$ & 2 & $4.76 \times 8.45$ & 30 \\
$2 \mathrm{c}$ & $114 \times 114$ & 2 & $3.18 \times 12.7$ & 30 \\
$3 \mathrm{a}$ & $114 \times 114$ & 2 & $6.35 \times 6.35$ & 45 \\
$3 \mathrm{~b}$ & $114 \times 114$ & 2 & $4.76 \times 8.45$ & 45 \\
$3 \mathrm{c}$ & $114 \times 114$ & 2 & $3.18 \times 12.7$ & 45 \\
$3 \mathrm{~d}$ & $114 \times 76$ & 2 & $6.35 \times 6.35$ & 45 \\
\hline
\end{tabular}

Material mild steel, $E=2.068 \times 10^{11} \mathrm{~N} / \mathrm{m}^{2}, v=0.3$ 
thick flat portion at the root retained ${ }^{A}($ ece fiefures 11 and 2$)$, and the models were rigidly fixed in a vice such that the entire surace area sollat portion at the root was in contact with the jaws of the vice; by this method of fixing the possibility of rigidbody motions of the object 'virrirg atactingean he completely eliminated. Figure 1 shows thedetails of the model fte present investigation are glate specinens as employed in

2.2. EXPERIMENTAL PROCEDURE

Figure 3 shows a schemat presenta a typical ......... f f carrying out the experiments. The diagramdisplays a $50 \mathrm{~mW}$ Helum-Neon laser (Spectral Physics) representing the monochromate wherent light soums al table. The associated optical components which ar. ................ 1. on the table are also shown in the same figure.

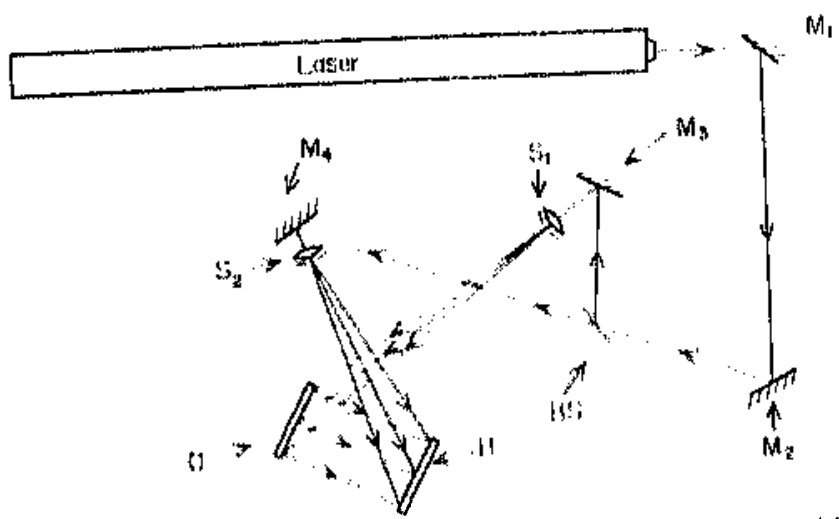

Figure ${ }^{3 .}$ schematic diagram of the holographic set-up. H, holographic plate: <), object; BS, beam splitter; $S_{1}, S_{2}$, spatial filters; $M_{1}, M_{2}, M_{3}, M_{4,}$ plane mirrors.

The object under investigation and the hologram plate holder in which the holographic plate was inserted were placed in the required position. The object and reference beams were then directed to the surfaces of the object and the photographic plate, respectively. The object to be tested was excited to its natural frequencies and the desired time-ayeraged holograms obtained after taking the usual precautions necessary in a holographic inter-

ferametric technique.

fhe ratio of intensities of the object and reference beams at the holographic plate was maintained approximately at $t$ in recording time-averaged holograms. The holographic

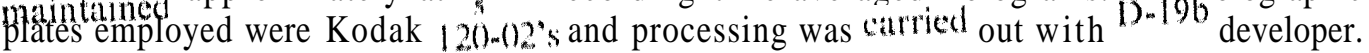
Typical exposure times ranged between $1(1-2)$ seconds,

\section{THIORETTAL, CONSIDFIRATIONS}

to carry ....t a comparative study with the experimental results a theoretical solution to the problem wats also obtained by the finite element method. three nodes, The plates were structurally idealized by using triangular elements with displacement each node being associated with three degrees of lrecdom: numely, the lateral were idealized by $W$ and the rotations about the $x$ and $y$ axes, $\partial W / \partial x$ and $\partial W / \partial y$. The ribs Whe displaceusing beam elements with three corresponding compatible degrees of freednm. A total of 128 ment $W$ is described by a cubic polynomial function in the
elements with 81 nodes was employed in the idealization. 
The stiffness and mass matrices were generated globally, the order of the matrices being reduced by a condensation procedure eliminating the rotational degrees of freedom. Eigenfrequencies and vectors were then determined through standard numerical procedures.

\section{RESULTS AND DISCUSSION}

Table 2 shows the experimental values of the frequencies for the cases 1,2a and $3 \mathrm{a}$, corresponding to the rib size $6.35 \times 6.35$, obtained by the quadrature method for the time-averaged holography. In order to avoid confusion in distinguishing the results obtained by the quadrature and real time methods, in our further discussion the terms "experimental results" must be considered to mean those obtained by the quadrature method for the time-averaged holography. Finite element results obtained for the cases $V=30^{\circ}$ and $45^{\circ}$, and the frequency values as determined by the real time holographic method for the case $\Psi=45^{\circ}$ are also

\section{TABLE 2}

Effect of sweep back angle on the frequencies $(\mathrm{Hz})$

\begin{tabular}{|c|c|c|c|c|}
\hline \multirow{2}{*}{$\begin{array}{c}\text { Case } 1 \\
\boldsymbol{\Psi}=\mathbf{0}^{\boldsymbol{*}} \\
\mathbf{E}\end{array}$} & \multicolumn{2}{|c|}{$\begin{array}{l}\text { Case 2a } \\
\psi_{:=30^{\prime \prime}}\end{array}$} & \multicolumn{2}{|c|}{$\begin{array}{l}\text { Case 3a } \\
\boldsymbol{\psi}_{\mathbf{~}=45^{\circ}}\end{array}$} \\
\hline & $\mathrm{E}$ & $\mathbf{T}$ & E & $T$ \\
\hline 115 & 160 & 169 & $180(190)$ & 165 \\
\hline 237 & 355 & 384 & $420(400)$ & 382 \\
\hline 682 & 831 & 897 & 860 (850) & 783 \\
\hline 882 & 893 & 978 & $1090(1040)$ & 992 \\
\hline 1178 & 1257 & 1332 & $1580(1605)$ & 1545 \\
\hline 1545 & 1630 & 1790 & $1755(1730)$ & 1731 \\
\hline 1900 & 2000 & 2170 & $2135(2180)$ & 2163 \\
\hline
\end{tabular}

E: Experimental; 'T': Theoretical.

given in the same table; for the real time case the values are given in the parentheses. It can be seen that the agreement between the experimental and theoretical results is reasonably good. While the percentage difference between the two sets of results for $\Psi=45^{\circ}$ varies from 1.3 to 9 the corresponding percentage values for the case $\psi=30^{\circ}$ ranges from a maximum of 9.0 to 5.45 . However, the frequency values as given by the real time holographic technique, which must be considered more accurate than either of the other two methods, are closer to those of theory except for the first and fifth modes. For $\Psi=0^{\circ}$ the theoretical results are not available; therefore no comparison can he made. Good agreement between the theoretically and experimentally determined mode shapes are also found for the cases $\Psi=30^{\circ}$ and $45^{\circ}$, as can be observed from ligures 4 to 7 which display modes 2 to 7 . The fundamental modes, which turn out to be cantilever bending modes, corresponding to $f=160 \mathrm{~Hz}$ $\left(\Psi=30^{\circ}\right)$ and $f=180 \mathrm{~Hz}\left(\Psi=45^{\prime \prime}\right)$ are not shown in these figures. The corresponding timeaveraged holograms arealso shown in the same figures (on the right side); in these holograms the bright fringes represent nodal lines while other fringes depicting contours of equal amplitudes represent antinodal regions. The full lines representing experimentally determined nodal lines (as shown on the left side of these figures) correspond to bright nodal lines as given in the holograms and in fact are reproduced from the latter. It can be noticed from these figures that modes 2,4 and 6 for $\psi-30^{\circ}$ and modes 2,4 and 7 for $\psi=45^{\circ}$ exhibit similarity in shapes to some extent. It may also be observed from the hologram for mode 4 

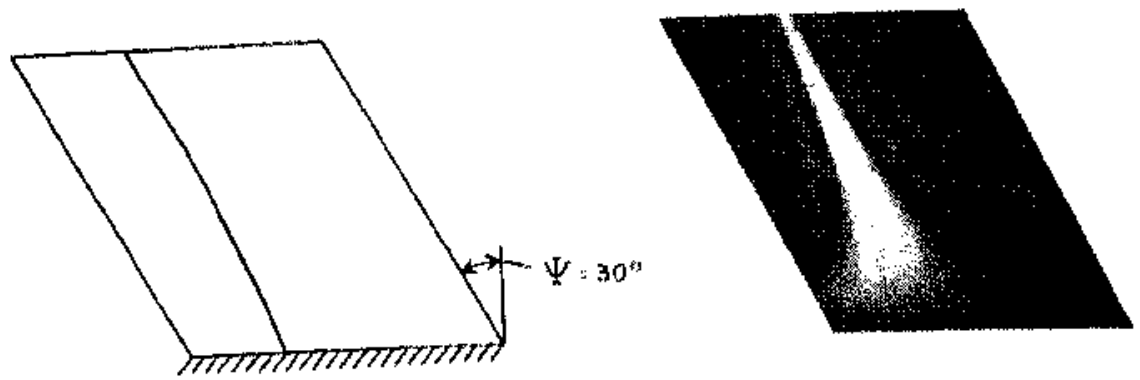

Morle $2,1=35542$ (3) $13 \ldots 1$ )
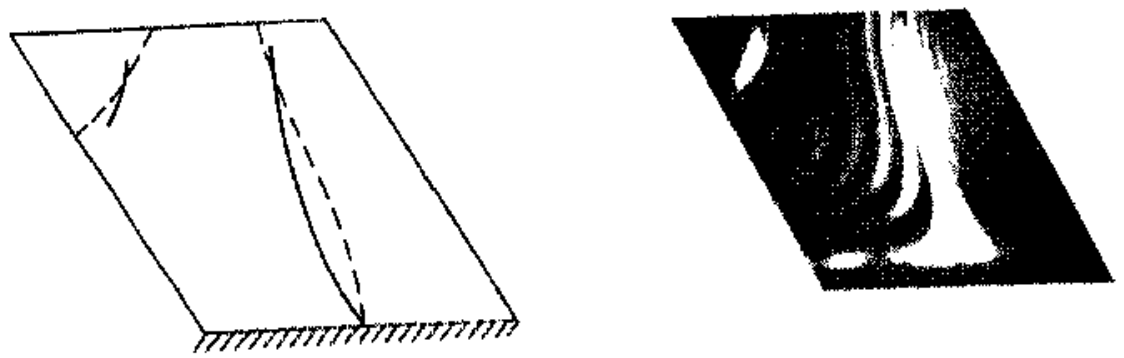

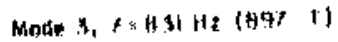
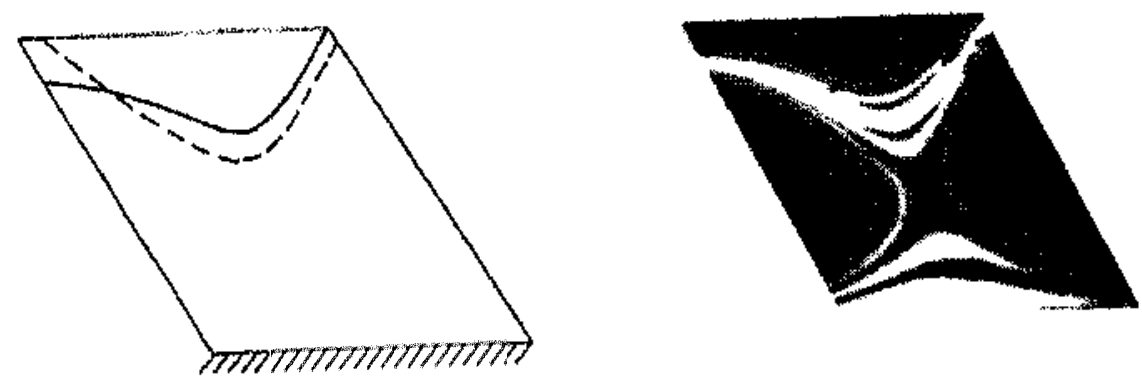

Mode $4, t=893$ H. $(978,1)$

Figure 4. Comparison of experimental and theoretical nodal patterns. $\chi^{\prime} .30^{\prime \prime}$ (ease $2 \mathrm{a}$ ), - - Experimental;........., theoretical,

that apart from the bright nodal line a, the root anchther witite fringe anpears immediately

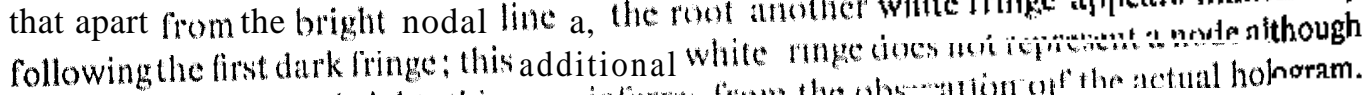
$i$, appears to be quite bright; this was inferre from the obs atlon of the actual holoram. No significant remarks can be made in respect of uthe modes. Figs shows modes1 to 6 for the case $V \quad 0$ ". It may be remarked here that while simme similar tyi moie shrapecan be observed between the eases " $\psi^{\prime} 30^{\prime \prime}$ and $4 \mathrm{~V}$. I ie mode $\mathrm{I}_{\mathrm{u}}$ \&s en pondi g to $\psi=0^{\circ}$ appear $\mathrm{U}$, he completely different from thense of the lorme cuss ex pot for three modes, which are similar $U$. the first, second and fourth modes for cases $\left.\psi^{\prime} \quad\right)^{\circ}$ and $45^{\circ}$ (sec Figures 4, (i and 8).

The effect of varying the rib stiffnesses with their masses " $k$. remstumt ${ }^{\text {is }}$ considered

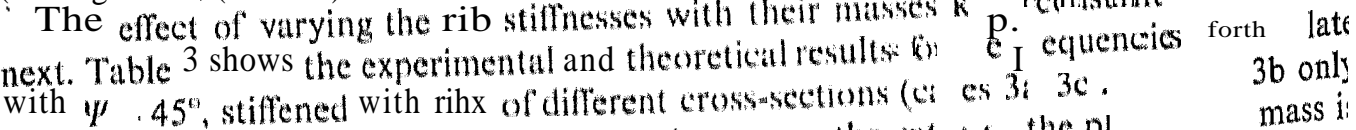
theoretical results are presented. In all the three cases the ":t it the pl mass $\mathrm{pl}$ maintained constant. The perentage difference between he theoretic imenta results for case $3 \mathrm{c}$ is found lo vary between a maximum of 8.777 to a very mall value. Cas 

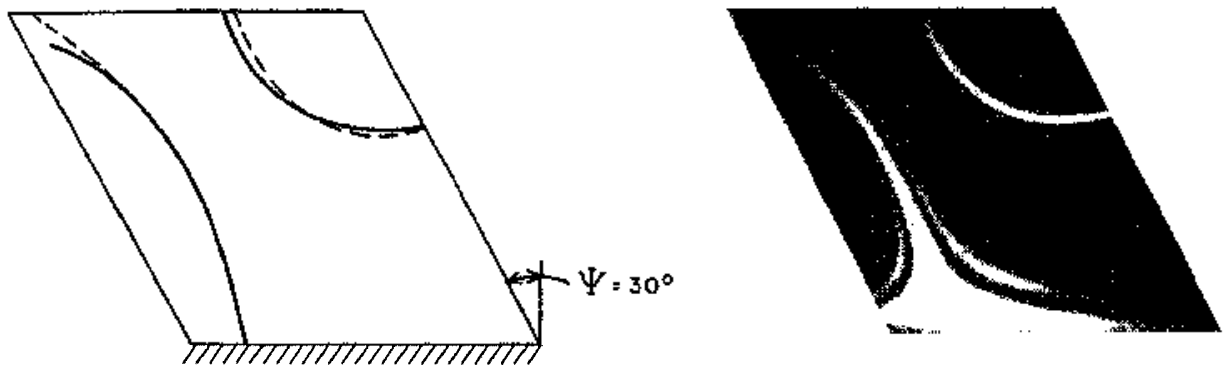

Mode $5, f=1257 \mathrm{~Hz}(1332-\mathrm{T})$
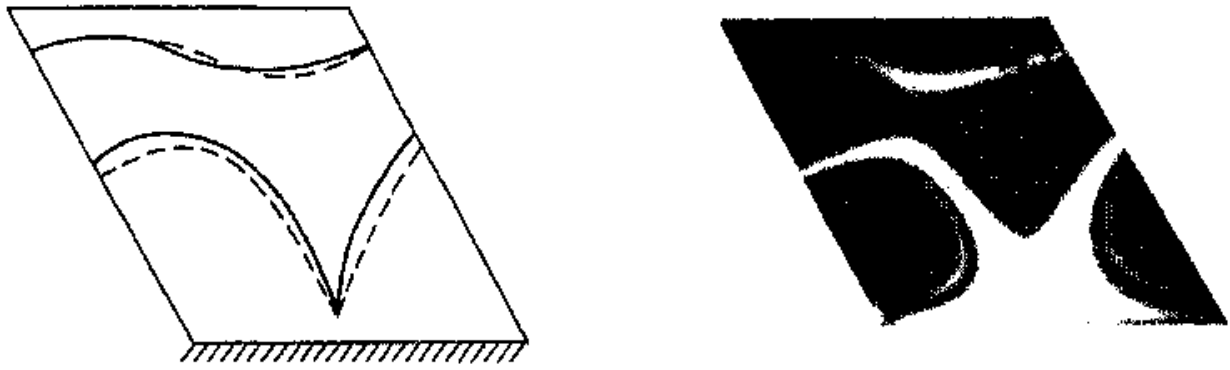

Mode $6, r=1630 \mathrm{~Hz}(1790-\mathrm{T})$
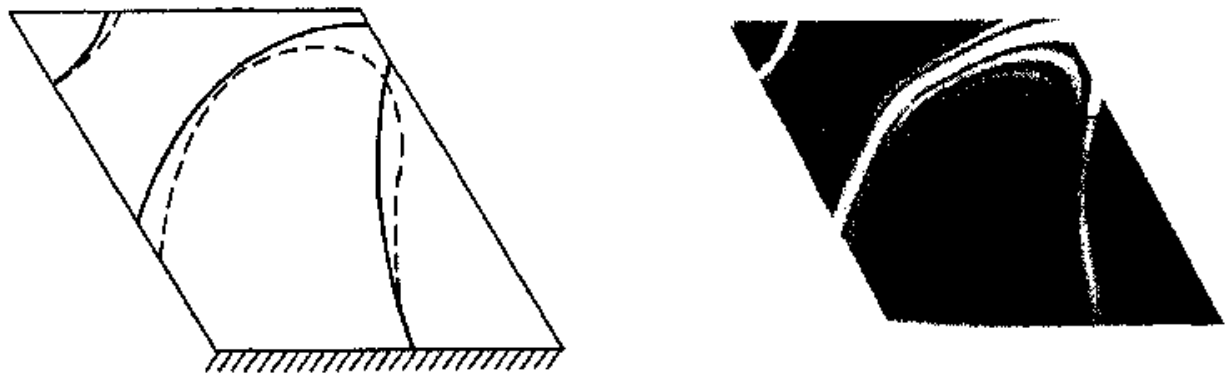

Mode $7, f=2000 \mathrm{~Hz}(2170-T)$

Figure 5. Comparison of experimental and theoretical nodal patterns. $\Psi^{\prime}=30^{\circ}$ (case 2a). - Experimental; …n...n.n, theoretical,

3a has already been considered earlier. As for the mode shapes, only minor .changes are observed when the results corresponding to eases $3 \mathrm{a}$ and $3 \mathrm{~b}$ are compared; the mode shapes for the latter are therefore not presented to save space. For case $3 \mathrm{c}$, it is interesting to note that the third mode deviates to some extent from the corresponding third one of case $3 \mathrm{a}$ (see Figure 9) but follows somewhat closely the third mode of $\Psi=30^{\circ}$ (case 2a), while only minor changes can be observed with regard to other modes, with absolutely no change in sequence in comparison with those of case $3 \mathrm{a}$; other mode shapes for case $3 \mathrm{c}$ are therefore not presented.

For the plate with $\psi=30^{\circ}$, the corresponding variation of rib stiffness (cases 2a-2c) seems to have only a small influence on the mode shapes without any accompanying changes in sequence; the mode shapes for the cases $2 \mathrm{~b}$ and $2 \mathrm{e}$ are therefore not presented to save space. The only change brought about is the expected increase in frequencies following the 

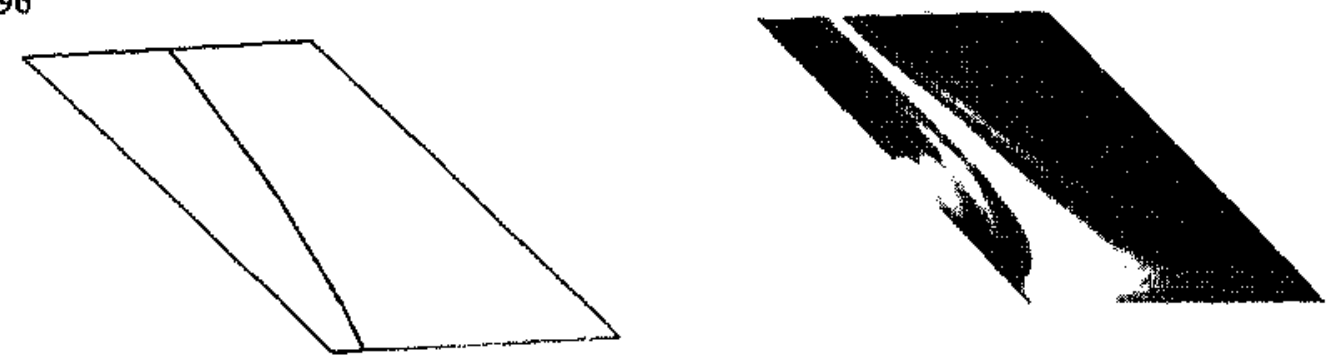

$\operatorname{mode} 2, t=420 \mathrm{HL}(3 \mathrm{H} 2 \cdot \mathrm{T})$
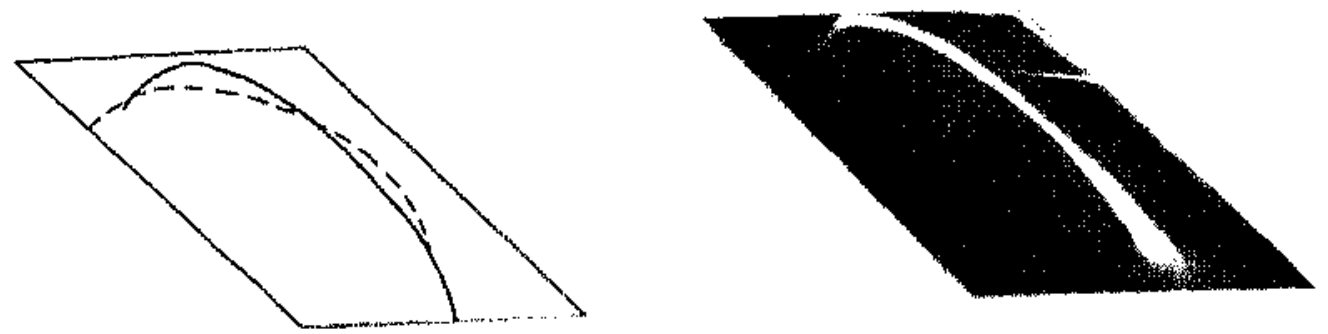

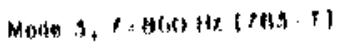
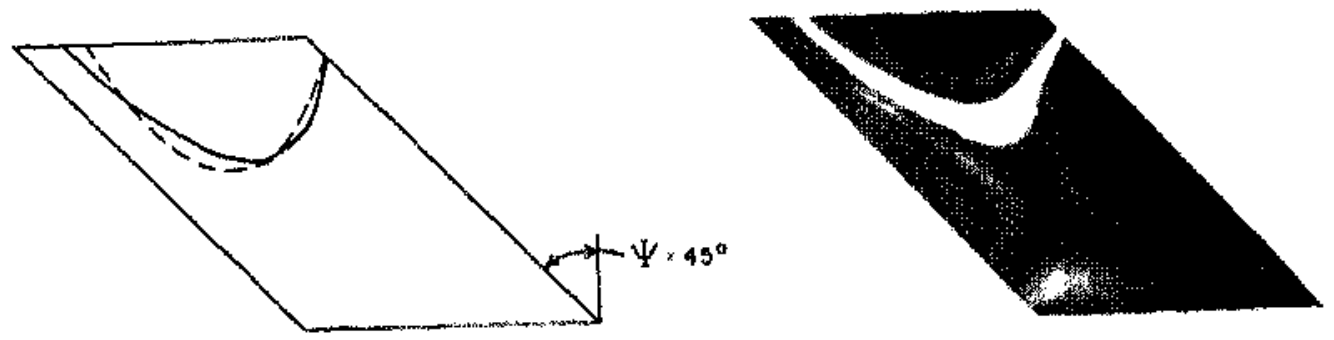

Mode 4, $t=1090 \mathrm{~Hz}(292 \times \mathrm{T})$

Figure 6. Comparison of experimental and theoretien nodal nattertis. 4 " 45 (ease $3 a$ ). " Experimental; $\ldots . . . . . . . .$, theoretical.

increase of stiffnesses as can be seen in Table 4, cases $2 a 2 a$. For the cases $2 b$ and $2 c$ frequencies were not determined experimentally and therefore only finite element results are pre-
sented, The results for case 2 a have alfoilly been sliscussed.

The influence of varying the aspect ritio on festumt frequencies ant sumble shapes is considered next, Reduction of the aspect ratio, as represented by case $3 \mathrm{~d}$, produces an increase in frequencies as expected and as Known in "ible 5. The fourth mode for this case, $\Psi^{\prime}-45^{\circ}$, appears as shown in Figure 10 (left) with $17631 \%$. As can be observed, there is considerable deviation from the corresponding one of cuse 3a (ligttre 10, right), Other than this departure, only minor changes take place in respect of other mode shapes, the senuence of modes remaining unaltered, Similar remarks can be made in respect of $\mathrm{V}{ }^{*} 30^{\circ}$ also; results for this case are not presented to save space.

Introduction of cuts at the root alters the boundary condition along the base width, thereby causing variation in the behaviour of the structure, the magnitude and type of changes depending upon the location and extent of cuts introduced. "This part of the investigation discussed next. The extent and location of cuts considered are shown in figure ${ }^{\text {. The }}$ 

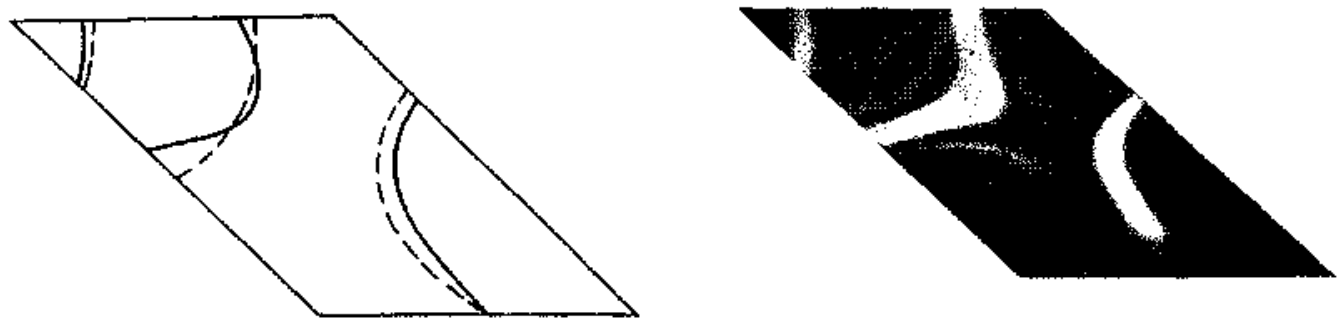

Mode $5, f: \mid 580 \mathrm{~Hz}(1545-T)$
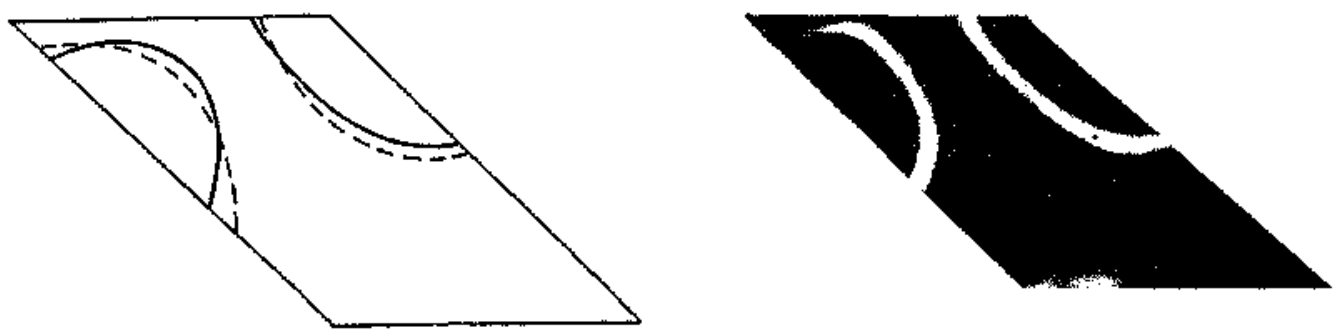

Mode $6, f=1755 \mathrm{~Hz}(1731-\mathrm{T})$
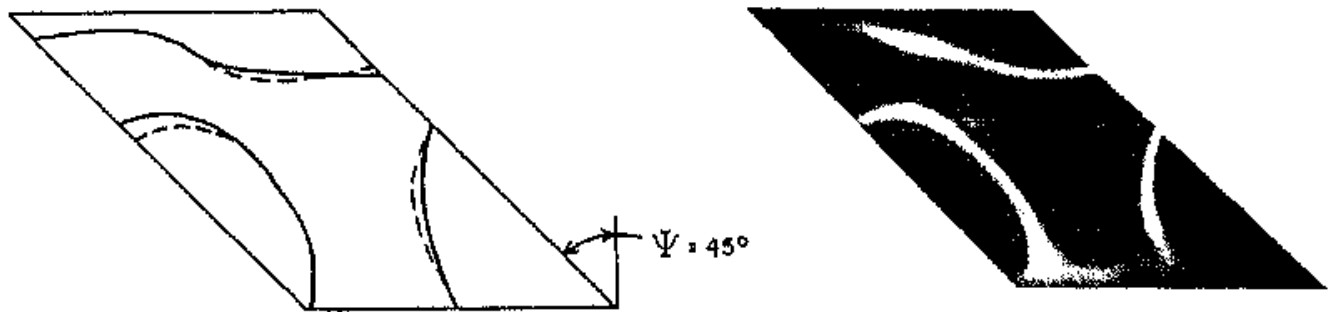

Mode $7, /=2135 \mathrm{~Hz}(2163-\mathrm{T})$

Figure 7. Comparison of experimental and theoretical nodal patterns. $\Psi=45^{\circ}$ (case 3a). - - Experimental; r.s....., theoretical.

resonant frequencies for cases $\mathrm{A}, \mathbf{B}$ and $\mathbf{C}$ corresponding to various cuts introduced at the root chord, are shown in Table 6; also shown in this table are the values for the uncut case, case $3 \mathrm{a}$, for comparison purposes; the frequencies for all these cases were determined by the real time holographic method. From this table it can be seen that there is a reduction in frequencies as the extent of cuts is increased, as can be expected. The second mode associated with cases A, B and C appears to be nearly the same as that for case 3a except at the root (see Figure 12, top). For case A the nodal line along the cut (first cut introduced) disappears. For case B the mode shape remains the same as for case A indicating the existence of the root nodal line along the second cut; this shows the second cut has no influence on the mode shape. It should be noticed that the first cut producing the change in the behaviour also happens to be located at the re-entrant corner which is the region of high stress concentration. Extension of the cut all along the base except in the neighbourhood of the rib allows the nodal line to exist only along the uncut zone (see again Figure 12, top, extreme right). Almost 
M. N. BAPU RAO RT AI.

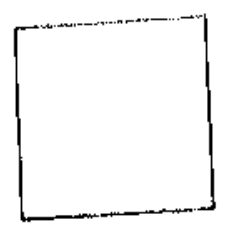

$f=115 \mathrm{~Hz}$

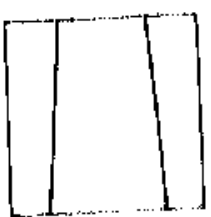

$f: 840 \mathrm{~Hz}$

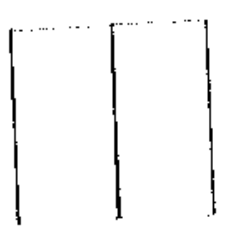

f 2.3711

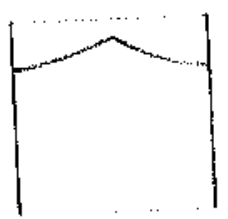

$t 110411$

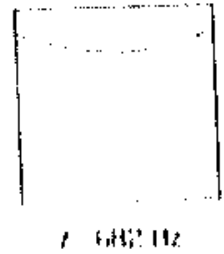

1 batillz

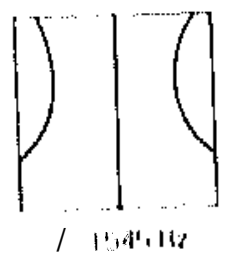

Figure $\mathrm{H}$, Mode shapes for case $1,\left(^{\prime \prime} 0\right)$.

TABL: 3

Effect of rib stilliness on the frequencies (Hz), $t^{\prime}=45^{\prime \prime}$

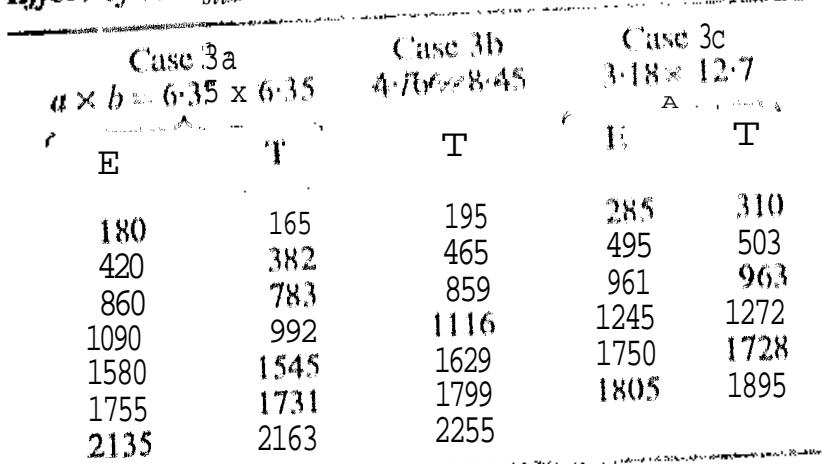

E: Experimental: ' $\mathrm{I}$ ': 'Theoretical.

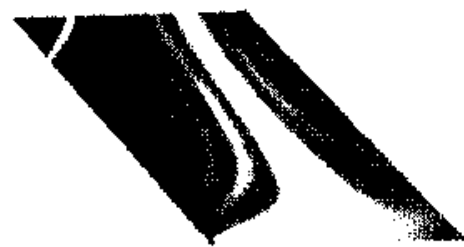

Cant $3 c, \Psi \times 43^{4}$

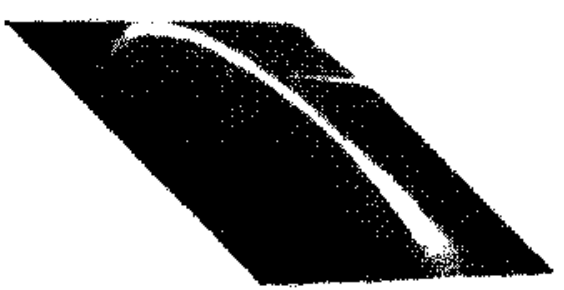

$\cos 30, \Psi=45^{\circ}$

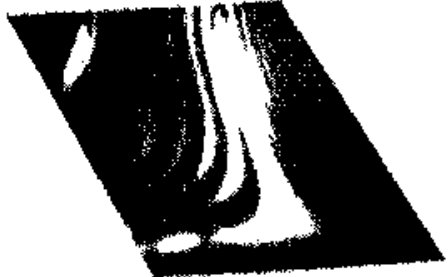

Case $20, \Psi: 30^{\circ}$

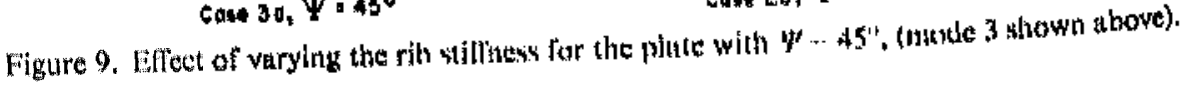


TABLE 4

Effect of rib stiffinesson the frequencies (Hz), $\Psi=30^{\circ}$

\begin{tabular}{|c|c|c|c|}
\hline \multicolumn{2}{|c|}{$\begin{array}{c}\text { Case } 2 a \\
6 \cdot 35 \times 6 \cdot 35\end{array}$} & \multirow{2}{*}{$\begin{array}{c}\text { Case } 2 \mathrm{~b} \\
4.76 \times 8.45 \\
\mathrm{~T}\end{array}$} & \multirow{2}{*}{$\begin{array}{c}\text { Case 2c } \\
3 \cdot 18 \times 12 \cdot 70 \\
\mathrm{~T}\end{array}$} \\
\hline$E$ & $T$ & & \\
\hline 160 & 169 & 203 & 272 \\
\hline 355 & 384 & 455 & 566 \\
\hline 831 & 897 & 983 & 1026 \\
\hline 893 & 978 & 1056 & 1146 \\
\hline 1257 & 1332 & 1504 & 1541 \\
\hline 1630 & 1790 & 2048 & 2281 \\
\hline 2000 & 2170 & 2428 & 2528 \\
\hline 2296 & 2502 & 2722 & 2959 \\
\hline
\end{tabular}

E: Experimental; T: Theoretical.

similar behaviour is noticed for the third mode also (see Figure 12, bottom). Figure 13 shows the comparison of mode shapes for various eases of cuts considered for modes 4 to 7. The fourth mode for cases A, B and C appear to be the same as that for the uncut case except for the expected reduction in the associated frequencies due to increased flexibilities arising from the cuts introduced; the higherflexibilities also permit additional modes to

TABLE 5

Effect of aspect ratio on the frequencies $(\mathrm{Hz})$, $\Psi=45^{\circ}$

\begin{tabular}{rr}
\hline Case 3a & Case $3 d$ \\
180 & 476 \\
420 & 806 \\
860 & 1371 \\
1090 & 1763 \\
\hline
\end{tabular}

occur at $f=1150 \mathrm{H} z$ and $f=1140 \mathrm{~Hz}$ in cases $\mathrm{B}$ and $\mathrm{C}$, respectively (the frequencies for the additional modes are given in the parentheses in Figure 13 and in Table 6). In the case of modes 5 and 6 similar behaviour can be noticed except forthe factthat the modes corresponding to those for the uncut case are not present in case $C$; this is indicated by a sign $\otimes$ in Figure 13 and Table 6 at appropriate locations. The phenomenon of mode disappearance
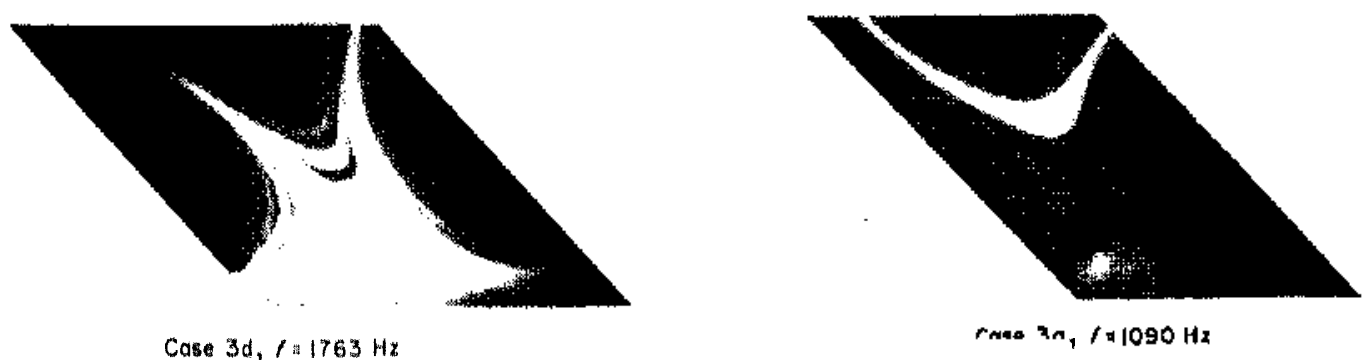

Case $3 d, f$ a $1763 \mathrm{~Hz}$

Figure 10. Elfect of varying the aspect ratio tor the plate with $\Psi^{\prime}=45^{\circ}$, (mode 4 shown above). 


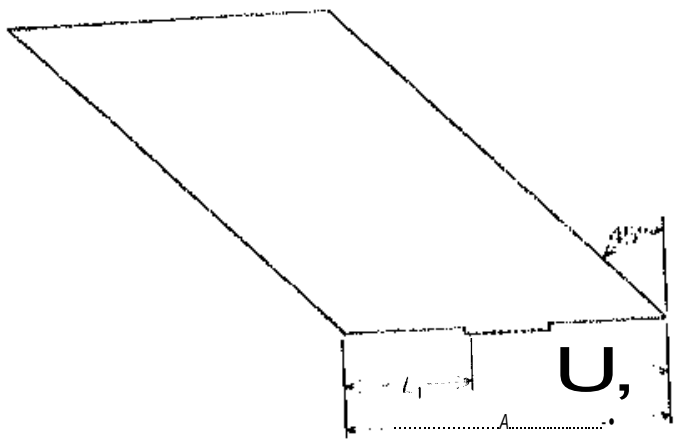

Figure 11. Dimensions of cuts at the root of the platt. Case A: $L_{22} \quad 0, / ., 28.6 \mathrm{~mm}$; case $\mathrm{B}: L_{1}=L_{2}=$ $28.6 \mathrm{~mm}$; case $C: L_{1}=L_{2}=44.5 \mathrm{~mm}$.

also occurs in the case of the 7 th mode for cases $B$ and $C$, followed by the appearance of additional modes as in the cases of he pre modes

marked in passing thit usu......... a a maximum of nine percent between experimentally and theoretically detemined values as sealized in the comparison study of

$$
\text { TABLI: } 6
$$

Effrot of cuts at the ront on she frofuencies (tw)

$$
y^{\prime \prime} . .45^{\prime \prime}
$$

\begin{tabular}{|c|c|c|c|}
\hline Casc $3 a$ & Case $A$ & Casc $B$ & $c^{\circ} \operatorname{arc} c^{\circ}$ \\
\hline 190 & 175 & 160 & 100 \\
\hline 400 & 385 & 360 & 340 \\
\hline 850 & 795 & 745 & 710 \\
\hline 1040 & 1025 & $040(11,50)$ & $905(1140)$ \\
\hline 1605 & 1515 & $1360(1510)$ & $1 .,\{12(01)\}$ \\
\hline 1730 & 1680 & $1555(1905)$ & $1:(1015)$ \\
\hline $2 \mathrm{HO}$ & 2145 & $\therefore \quad(2145)$ & $1.1(1475)$ \\
\hline
\end{tabular}

fhequencies can be reduced by the following considerations. Fequencies determined from accurannedy-Pancu technique in place of the quadrature response method can probitinedore using the experimental results. Very accurate values for frequencies can also be

by holographic technique, as has licen done
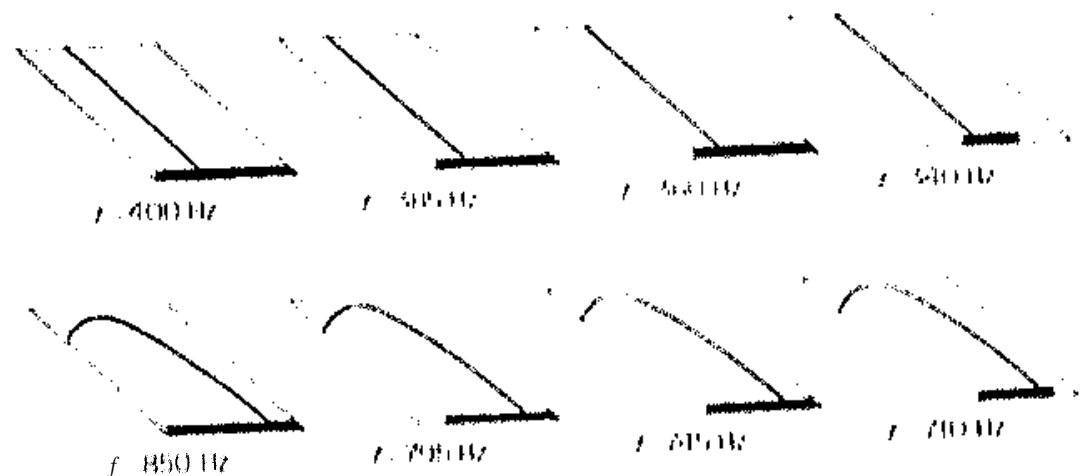

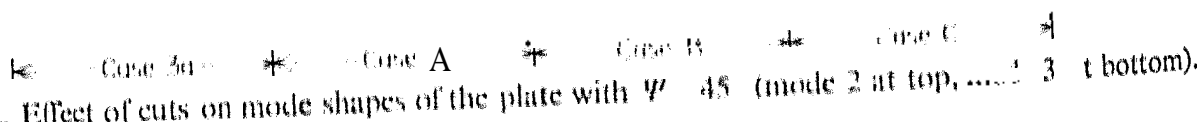
Higure 12. 1:llod of
Root nodal line 


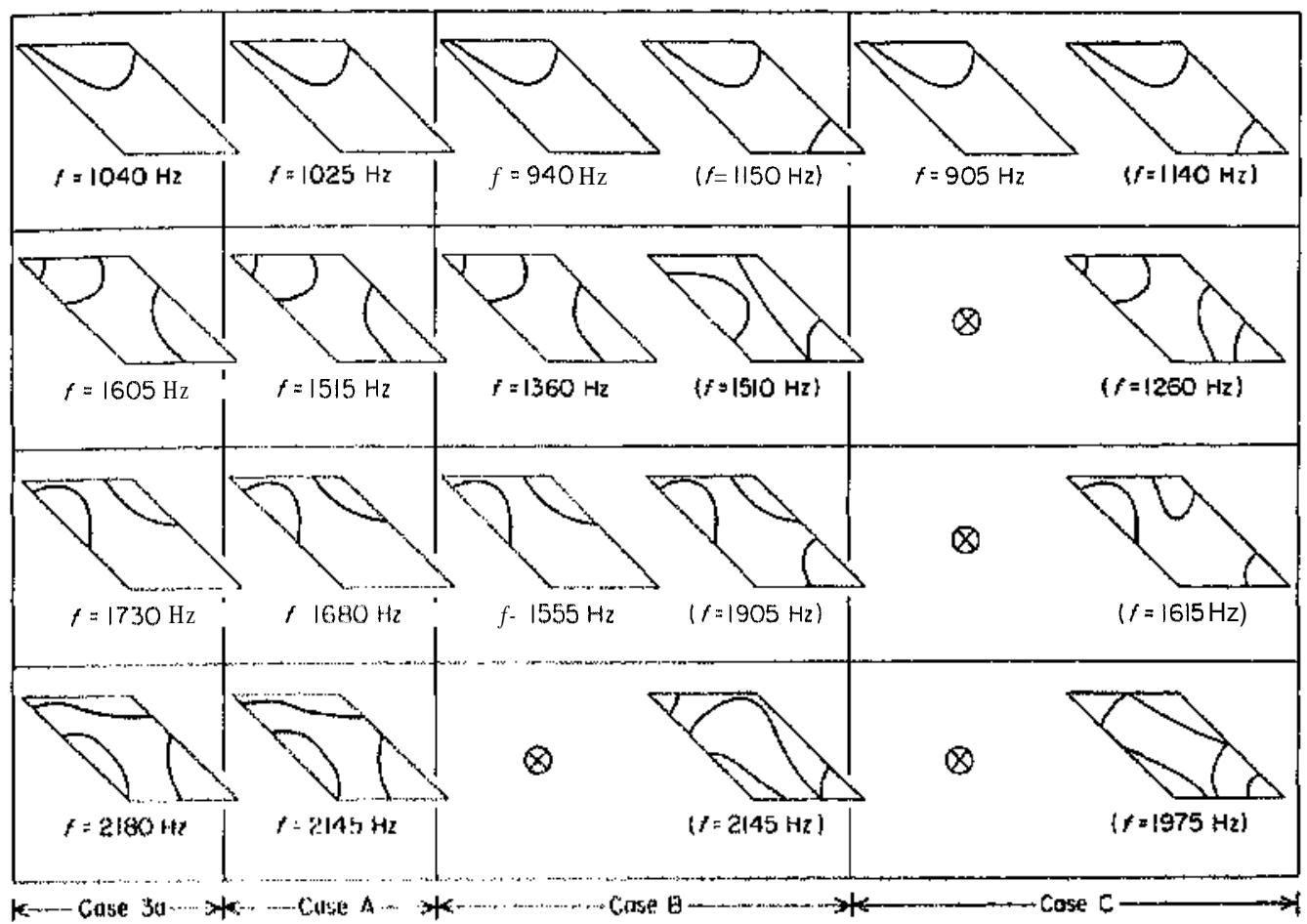

Figure 13. Effect of cuts on mode shapes of the plate with $\Psi^{\prime}=45$ " (modes 4-7 from top to bottom).

theoretically determined results, simple plate and beam bending elements have been employed in the present analysis. However, use of higher order elements, in which both membrane and bending deformations associated with higher order of degrees of freedom are considered, gives rise to more accurately determined results. Inclusion of both membrane and bending plate deformations becomes more meaningful as the value of the rib depth increases for given plate sizes, especially when the value of the former approaches the order of the plate dimensions. It may be mentioned here that Olson and Hazell [5] obtained very accurate results in vibrational studies of rib-stiffened square plates through the use of high precision plate and beam elements, both membrane and bending deformation being included in the plate element. Nevertheless the present studies have provided insight into the vibrational behaviour of the various cases of rib-stiffened plates considered.

\section{ACKNOWLEDGMENT}

The authors would like to express their grateful thanks to Mr B. R. Somashekar, Head of Structures, National Aeronautical Laboratory, Bangalore, for his interest in this investigation and also to The Aeronautics Resetrch and Development Board for the financial support provided for carrying out this investigation. The authors also wish to thank Miss J. R. Kulkarni for plotting the Uleoretical mode shapes,

\section{RERLRENCWS}

1. G. M. LINDniri and M, D. OLSON 1967 National Research Council of Canada Aero Report $L, R-492$. Vibration modes and random response of u multi-bay panel system using finite elements.

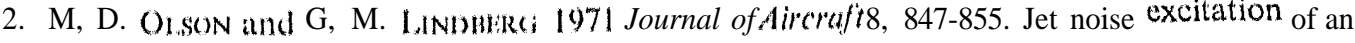
integrally stiffened panel.

3. R. N. YURKovict, J. H. SCHMIDT and A. R. ZAK 1971 Journal of Aircraf8, 149-155. Dynamic analysis of stiflened panel structures. 
4 S. DURVASULA 1971 Journal ofthe Indian Rocket Society 11, 13-32. Vibration of shaft-supported low aspect ratio contron surtaces.

5. M. D. OLSON and C. R. HAzkt.L. 1977 journal of Sound and Vilhration 50, 43 61. Vibration studies on some integre. ffened plates.

6. R. L. Powet and K. A. Sterson 1965 Journal of the Optical Socity of America 55, 15931598. Interferometric vibration andysis by wavefronl recomstruction. 